\title{
Social Class and Household Consumption: Experience from China
}

\author{
Hailiang Yao \\ Central University of Finance and Economics, Beijing, China \\ Email: yaohailiang83@126.com
}

How to cite this paper: Yao, H.L. (2020) Social Class and Household Consumption: Experience from China. Open Journal of Social Sciences, 8, 262-271.

https://doi.org/10.4236/jss.2020.81019

Received: December 18, 2019

Accepted: January 14, 2020

Published: January 17, 2020

Copyright () 2020 by author(s) and Scientific Research Publishing Inc. This work is licensed under the Creative Commons Attribution International License (CC BY 4.0).

http://creativecommons.org/licenses/by/4.0/

\begin{abstract}
This paper empirically analyzes the influences of Chinese residents' social class on their household consumption. According to the data of Chinese Family Panel Studies (CFPS) in 2016, considering the endogenous possibility of the social class on household consumption, the regression results of instrumental variables indicate that the social class of Chinese residents has a significant positive impact on household consumption. As for the policy implication behind this paper, when creating relevant consumption policies, responsible government departments in China should fully consider the possibility and complexity of the social class influence of residents on the policy effectiveness.
\end{abstract}

\section{Keywords}

Social Class, Household Consumption, Chinese Households

\section{Introduction}

The report of the 19th National Congress of the Communist Party of China made a major judgement of "socialism with Chinese characteristics entering a new era", clearly stating that "the main contradictions in Chinese society have been transformed into the growing needs of the people and the imbalanced and inadequate development contradiction". The connotation of a better life is undoubtedly rich, but from the economic point of view, its core lies in expanding household consumption and thereby improving residents' welfare. For this reason, the report of the Nineteenth National Congress of the Communist Party of China proposes to "improve the mechanism and mechanism for promoting consumption and enhance the fundamental role of consumption in economic development", which shows that China's current emphasis on consumption has reached an unprecedented high level. 
According to the theory of consumer behaviors, the research on the influential factors of consumption has long received the focus of the academic field, all developing from the life cycle model of Ando et al. [1]. The theory of neoclassical economics indicates that the decision-making process of personal consumption is mainly determined by economic factors such as consumer incomes, budget constraints and relative commodity prices. Apart from economic theoretical research, some references inside and outside China have also examined the impacts of different social-demographic and economic characteristics on household consumption from the perspective of micro empirical research. These social-demographic characteristics mainly include educational backgrounds [2], race, age and gender; economic factors mainly include residents' income and assets [3]. These empirical studies have discovered that these heterogeneous features, in fact, have a significant impact on household consumption. If we draw a conclusion of the above literature on the influential factors of household consumption, we can find that although some previous studies have taken a micro perspective to analyze the influential factors of family consumption from the characteristics of individual heterogeneity, an essential factor is often ignored among many micro factors: the social class of residents.

A social class refers to the ranking of individuals or groups on how they are generally recognized in society. People will rank in society according to certain well-recognized standards, so as to determine each person's social class. The social class is usually the concept existing in a group. Each member of the group may have different ranks in the simple order, but they also enjoy the social stratum obtained as part of the group. Meanwhile, they need to mutually restrict the members of the group and control the new memberships to shape or maintain the image and authority of their group in the society.

From the sociological perspective, consumers are not only part of the society, but also individuals with a specific class and certain images. One cannot conduct consumption inconsistent with their social class. The consumption behaviors from different social classes will be displayed by different signs and symbols, whether it is conspicuous consumption such as boasting and feasting, rational or irrational consumption, or people's commonly used language, favorite outfits, preferred dishes, popular music, their social network, the residence and their compounds, favorite sports, prevalent TV programs, newspapers or magazines, all of which show the hierarchy of consumption due to the different social classes of consumers. People interact more with other members of their own groups or social classes. Those in the same social class also tend to share the same social experience and roles as well as similar social attributes and attitudes.

From the possible influence mechanism of social class on household consumption, the level of social class is reflected in the amount of economic resources and political resources occupied by individuals. Even if the social class does not directly enter the utility function, the higher social class can enjoy more social resources without allocated in the market [4] [5]. People of higher social 
class may have more consumption categories and flexibility [6]. In addition, in order to further meet the diversified consumption demand, the higher social class tends to live in areas with more abundant product supply, which further promotes family consumption from the supply side. According to the network external theory of Rauch \& Scoppa [7], the consumption decisions of individuals or group consumers with similar social classes may be more mutually influenced. Through the above process or the influence mechanism, the social "gradient" in household consumption can be reflected in practice, that is, the higher the social class of residents, the more likely they are to own more consumption categories and consumption flexibility, and the higher the household consumption results from the external characteristics of it.

There is a lack of current research related to the influence of social class on household consumption inside and outside China. Although some researches emphasize that social class has an impact on household consumption, there is a lack of case studies and empirical evidence on this in the literature, especially evidence from micro statistics. To fill in the gaps of the references, this paper applies the data of Chinese Family Panel Studies (CFPS) in 2016 to empirically analyze the impact of social class on Chinese household consumption from a micro perspective. Based on the 2016 CFPS questionnaire, we chose the local social status of residents as the explanatory variable to reflect their social class, taking into account the demographic characteristics of residents, such as genders, ages, marital statuses, and health conditions to explore the impact of Chinese residents' social class on household consumption. In the regression, we will not only control the influence of population characteristics on household consumption, but also consider the endogenous possibility of social class affected by household consumption. Moreover, we will also discuss the influence of social class on other consumption items of the family and the influence of population characteristics on household consumption.

The potential contribution of this paper may be that, taking Chinese families as samples, we may not only improve the existing empirical research based on Chinese families, but also provide a new aspect to explain Chinese family consumption behavior, which works as a reference for the promotion of domestic demand, well-being and structural reform of the supply. Furthermore, by focusing on the important family economic behavior of household consumption, we can not only make up for the lack of neglecting the social class variables in the existing family consumption literature, but also expand the sociology research scope, and build a bridge between the social class connected with sociology and the family consumption in economics.

It is worth emphasizing that it is of great practical significance to select China as the research target. Compared with the developed countries in the West, the Chinese government plays a more prominent and important role in many aspects such as industrial development and domestic demand, yet its policy effectiveness depends not only on the planning design and specific implementation 
of the policy subject, or the government, but also on the heterogeneity characteristics of the policy object, or the residents. The social stratum of the policy target should not be ignored. Moreover, the differences of social classes of Chinese residents will significantly lead to their different family consumption. Therefore, it is necessary for the Chinese government to take the social stratum of the policy object into consideration when making the policy, so as to ensure the expected effect of the policy.

The structure of this paper is as follows: the second part describes and analyzes the sample data; the third part introduces the measurement model; the fourth part reports the empirical analysis results such as benchmark regression and the endogeneity discussion; and finally it is about the conclusion and policy recommendations.

\section{Statistics, Variables and Data Analysis}

\subsection{Statistics}

The data applied in this paper are from the micro household survey program named Chinese Family Panel Studies (CFPS) implemented by Institute of Social Science Survey (ISSS) of Peking University in 2016, which has investigated in details the economic situation, demographic characteristics and subjective attitudes of 45,319 residents in 14,763 households in China. This paper narrows down on the impact of social class on household consumption, in which demographic characteristics such as social class of residents mainly generate from the adult questionnaire data while economic characteristics such as household consumption are from the household questionnaire data. To achieve this, we matched the adult questionnaire data with the family questionnaire data according to the family code, and removed the samples with incomplete information. Eventually, we obtained the individual observation data of 35,051 respondents, which constitutes the samples analyzed in the current paper.

\subsection{Variables}

First, as for the structure of household consumption of the explained variable, we took the logarithm form of the total household expenditure in the past year (ln_family_con) in the questionnaire as the explained variable. Secondly, as for the social class explanatory variables that we pay attention to, we choose the social status of residents in the local area as the explanatory variables reflecting the social stratum (social_stra) in the questionnaire. This variable is based on the score of the subjective evaluation by the interviewees. For the sake of comparison, the values are unified between 1 and 5 . The higher the score, the higher the social stratum of residents. We deleted the sample questionnaires without answers.

Thirdly, considering that the household consumption is also affected by other factors than social class, we selected a series of factors such as demographic characteristics of residents and family financial status as control variables referring to relevant literature, in order to consider as many the heterogeneity characteris- 
tics of respondents as possible. In the demographic variables of residents, it mainly includes: whether the residents are males (genders), and when the residents are male, the value is 1 , otherwise 0 . The age of the residents should be counted as how the Western world counts their ages. Considering the possible nonlinear effects of age, we also set the square term of resident age (squ_age). If the residents are married, 1 will be taken for married or cohabiting residents, and 0 for the unmarried, divorced or widowed. The years of educational backgrounds (eduy) of residents are the number of years they have received education. If they have not received any formal education, the value is 0 . The education level to primary schools is 6 . The education level to junior high schools is 9 . The education level of senior high schools is 12 . The education level of colleges is 15. The education level of Bachelor degrees is 16. The education level of Master degrees and above is 19. In terms of whether residents are healthy (health) or whether they are registered in towns or cities (urban), if the answer is yes, the value is 1 , otherwise 0 . The number of family members (nfamily) is the number of permanent residents. When the profession of residents belongs to the Party or government departments/ people's organizations/army/public institutions, the assignment is 1 , and the rest is 0 . If the resident has an administrative/management position (manager), the value is 1 , otherwise 0 . If the resident is employed, 1 will be taken; otherwise 0 . If the resident often surfs on the Internet (netdummy), 1 will be taken, otherwise 0 will be taken. In the financial variables of households, income is the total income of households in the past year, with the unit of every 10,000 yuan. Asset (asset) is the market value of the current assets of the family, with the unit of every 10,000 yuan. Unlike household income and assets, many sample households have no debt, so the value is 0 when the household has no debt, otherwise it is 1 .

In addition, because of the symbolic nature of household consumption, it can show its social advantages and may play a role in social classes. Since the upper social class needs to maintain the status, or the middle class or the lower class narrow the gap between the upper class by imitating the consumption of the upper class, family consumption may have an impact on the social class, so the social class of residents may be endogenous in their family consumption. For this reason, this paper chooses the interviewee's interpersonal level as an instrumental variable (interpersonal). This variable is based on the scores of the respondents. For comparison, the values are all between 1 and 7. The higher the score, the higher the level of hospitality of residents.

\subsection{Data Analysis}

Table 1 shows the descriptive statistical results of sample variables. The statistical results of 2016 samples showed that the logarithmic mean of household consumption was 10.18; half of the participants were male; the average age of residents was about $45 ; 76 \%$ of the residents were married; the average education period was 6 years; $67 \%$ of the residents were in good health conditions; $49 \%$ of the residents were registered as urban citizens; the average number of family 
Table 1. Descriptive statistical results of variables.

\begin{tabular}{|c|c|c|c|c|}
\hline Variable & Mean & Standard Deviation & Minimum & Maximum \\
\hline ln_family_con & 10.18 & 1.04 & 1.10 & 15.32 \\
\hline social_stra & 2.79 & 1.07 & 1 & 5 \\
\hline gender & 0.50 & 0.50 & 0 & 1 \\
\hline age & 45.81 & 16.88 & 16 & 98 \\
\hline squ_age & 2383.23 & 1614.08 & 256 & 9604 \\
\hline married & 0.76 & 0.43 & 0 & 1 \\
\hline eduy & 6.38 & 5.03 & 0 & 19 \\
\hline health & 0.67 & 0.47 & 0 & 1 \\
\hline urban & 0.49 & 0.50 & 0 & 1 \\
\hline nfamily & 4.33 & 2.05 & 1 & 19 \\
\hline manager & 0.02 & 0.13 & 0 & 1 \\
\hline employed & 0.65 & 0.48 & 0 & 1 \\
\hline netdummy & 0.44 & 0.50 & 0 & 1 \\
\hline income & 6.30 & 12.90 & 0 & 833.60 \\
\hline asset & 41.04 & 180.84 & 0 & 10001 \\
\hline debts & 0.36 & 0.48 & 0 & 1 \\
\hline interpersonal & 5.82 & 1.14 & 1 & 7 \\
\hline
\end{tabular}

members was $5 ; 2 \%$ of the residents have administrative or management positions; $65 \%$ of the residents were employed; $44 \%$ of the residents had access to Internet; the income, assets and liabilities of different families had huge gaps; the overall level of hospitality of residents was above the average.

\section{Measurement Model}

\subsection{Basic Models}

According to the continuous variable form of the logarithm of household consumption, we refer to the practice of scholars such as Treiman [8] and explore the impact of changes in the social status of residents on the percentage change in household leisure consumption while controlling various demographic and economic characteristics.

The OLS model set as follows:

$$
\text { ln_family_con }{ }_{i}=\beta_{0}+\beta_{1} \text { social_stra }_{i}+X_{i} \eta+\mu_{i} \mu_{i} \sim N(0,1)
$$

Among them, ln_family_con refers to the logarithm of household consumption of the explained variable; social_stra is the explanatory variable of social class as the current focus; $X$ is the other control variable that affects household consumption. According to the previous theoretical analysis on the influence of social class on household consumption, we expected that the influence of social class on the logarithm of household consumption should be significantly positive. 


\subsection{Endogeneity}

According to the previous discussion, the social class of residents may be endogenous in their family consumption. This means that the consumption performance of households may affect the social stratum of residents. We chose the interviewee's hospitality as an instrumental variable, because groups with similar social strata usually have similar social experience and roles, and their speech manners and behaviors should be consistent with the etiquette and customs of their status. The level of hospitality reflects the ability of interpersonal communication, which may have an essential impact on the consolidation and promotion of social stratum. This explains, the level of hospitality (interpersonal) of instrumental variable is directly related to the social stratum (social_stra) of endogenous variable. However, the level of hospitality is not enough to change their family consumption, that is, the instrumental variable is not directly related to the explained variable. We also notice that instrumental variables can only affect the explained variables through the social class, that is, through the endogenous variables. In view of the above three criteria to determine whether the instrumental variable is suitable (the instrumental variable is directly related to the endogenous variable, or it is not directly related to the explained variable, or it can only affect the explained variable by influencing the endogenous variable), we provide the supporting test results below.

In consideration of the endogeneity of the residents' social class to their household consumption, we used the instrumental variable method to solve the endogeneity problem. The instrumental variable method is an effective method for solving endogenous problems. This method covers the 2SLS method. Its connotation is that when endogenous problems are generated by the endogenous variables and error terms in the model, according to relevant theories and data, find an explanation The proxy variables that are variable but not related to the random error term, that is, instrumental variables, and then the Hausman test is used to determine whether the instrumental variables are appropriate [9].

The 2SLS regression model is set as follows:

$$
\begin{aligned}
\ln \_ \text {family_con }_{i} & =\beta_{0}+\beta_{1}{\widehat{\text { social_stra }_{i}}}+X_{i} \eta+\mu_{i}+\beta_{2} v_{i} \text { social_stra }_{i} \\
& =\pi_{0}+\pi_{1} \text { interpersonal }_{i}+v_{i}
\end{aligned}
$$

Model (2) consists of two stages: first, the social stratum (social_stra) of the endogenous explanatory variable regresses the hospitality level (interpersonal) of the instrumental variable, and second, the fitting value of the first stage is regressed by (ln_family_con). When the P value of the Hausman test is less than 0.05 , it is considered that there is an endogenous issue in the social stratum of the explanatory variable, and vice versa.

\section{Evidence Analysis}

\subsection{Benchmark Regression Results}

Model (1) in Table 2 is based on the regression model without considering the 
Table 2. Mechanism of household consumption.

\begin{tabular}{|c|c|c|}
\hline \multirow{2}{*}{ Explained Variables } & Model (1): OLS Regression & Model (2): 2SLS Regression \\
\hline & ln_family_con & ln_family_con \\
\hline \multirow[t]{2}{*}{ social_stra } & $0.0141^{\star *}$ & $0.936^{* * *}$ \\
\hline & $(2.76)$ & $(5.65)$ \\
\hline \multirow[t]{2}{*}{ gender } & $-0.0366^{* * *}$ & 0.0294 \\
\hline & $(-3.32)$ & $(1.48)$ \\
\hline \multirow[t]{2}{*}{ age } & $0.0155^{\star * *}$ & $0.0187^{\star * *}$ \\
\hline & $(6.76)$ & $(5.55)$ \\
\hline \multirow[t]{2}{*}{ squ_age } & $-0.000141^{\star * *}$ & $-0.000287^{* * *}$ \\
\hline & $(-6.17)$ & $(-6.78)$ \\
\hline \multirow[t]{2}{*}{ married } & $0.0898^{\star * *}$ & 0.0263 \\
\hline & $(5.46)$ & $(0.99)$ \\
\hline \multirow[t]{2}{*}{ eduy } & $0.0266^{\star * *}$ & $0.0240^{* * *}$ \\
\hline & $(21.65)$ & $(12.96)$ \\
\hline \multirow[t]{2}{*}{ health } & 0.0104 & $-0.183^{\star * *}$ \\
\hline & $(0.84)$ & $(-4.68)$ \\
\hline \multirow[t]{2}{*}{ urban } & $0.340^{* * *}$ & $0.493^{* * *}$ \\
\hline & $(29.41)$ & $(15.31)$ \\
\hline \multirow[t]{2}{*}{ nfamily } & $0.0802^{\star * *}$ & $0.0701^{\star * *}$ \\
\hline & $(28.72)$ & $(15.79)$ \\
\hline \multirow[t]{2}{*}{ manager } & $0.135^{\star *}$ & -0.0838 \\
\hline & $(3.17)$ & $(-1.14)$ \\
\hline \multirow[t]{2}{*}{ employed } & $-0.113^{* * *}$ & $-0.166^{* * *}$ \\
\hline & $(-8.89)$ & $(-7.99)$ \\
\hline \multirow[t]{2}{*}{ netdummy } & $0.323^{* * *}$ & $0.386^{* * *}$ \\
\hline & $(21.45)$ & $(15.69)$ \\
\hline \multirow[t]{2}{*}{ income } & $0.0182^{\star * *}$ & $0.0157^{* * *}$ \\
\hline & $(43.48)$ & $(20.85)$ \\
\hline \multirow[t]{2}{*}{ asset } & $0.000443^{* * *}$ & $0.000353^{* * *}$ \\
\hline & $(12.50)$ & $(6.54)$ \\
\hline \multirow[t]{2}{*}{ debts } & $0.260^{* * *}$ & $0.254^{* * *}$ \\
\hline & $(22.88)$ & $(15.36)$ \\
\hline \multirow[t]{2}{*}{ _cons } & $8.739^{* * *}$ & $6.522^{* * *}$ \\
\hline & $(162.68)$ & (16.07) \\
\hline$N$ & 29540 & 29540 \\
\hline
\end{tabular}

$t$ statistics in parentheses, ${ }^{*} \mathrm{p}<0.05,{ }^{* *} \mathrm{p}<0.01,{ }^{* * *} \mathrm{p}<0.001$, chi2 $(1)=(\mathrm{b}-\mathrm{B})^{\prime}\left[\left(\mathrm{V} \_\mathrm{b}-\mathrm{V} \_\mathrm{B}\right)^{\wedge}(-1)\right](\mathrm{b}-\mathrm{B})=$ 65.32; Prob $>$ chi $2=0.0000$.

possibility of endogeneity of heterogeneous social classes, and estimates the impact of social classes on household consumption in 2016. The control variables 
in the model include a series of variables such as demographic characteristics of residents and family financial status.

According to the regression results of Model (1), there is a significant positive correlation between residents' social class and household consumption: when residents' social class was higher, their family consumption level was also higher, which is consistent with our previous prediction. More specifically, for each level of improvement in the social class of residents, household consumption increased by 1.41 percentage. In addition to social class, most other factors also have a significant positive impact on their family consumption, including the age of residents, whether they are married, years of receiving education, registration status, family sizes, whether they have administrative or management positions, whether they have access to the Internet, income, assets, whether they are in debt. However, three factors have a significant negative impact on their family consumption: the genders of residents, the square item of age, and whether they are employed.

\subsection{Endogeneity Test}

Considering the endogenous possibility of the social class of residents to cultural consumption, Model (2) in Table 2 presented the regression results of instrumental variables considering the endogeneity. It can be seen from the regression results that the instrumental variable was significantly positive to the 2SLS regression coefficient of the explained variable. From the results of endogeneity test, the $\mathrm{P}$ value of Hausman test is less than 0.05 , which indicates that there exists endogeneity in social class, the setting of instrumental variables is reasonable, and the endogeneity issue is effectively solved. The regression results of instrumental variables show that the social class of residents has a significant positive impact on household consumption.

\section{Conclusions and Policy Implications}

It has become one of the important tasks of the Chinese government's macro-control on economy enhancing the structural reform of the supply side, improving the mechanisms and mechanisms for promoting consumption, enhancing the fundamental role of consumption in economic development, and expanding household consumption to improve the level of welfare of residents. The existing literature mainly focused on the economic characteristics and demographic characteristics (such as age, gender and the education level), but often ignored the influence of social classes. Based on this, this paper may not only expand the relevant literature about social classes, but also supplement the household consumption literature.

Based on the cross-sectional data of the CFPS micro household survey in 2016, this paper systematically investigated the specific impacts of social classes on household consumption in China for the first time. In consideration of the possibility that the social class is endogenous in the family consumption, this 
paper designed an instrumental variable measurement model to test and deal with the possibility of the social class endogeneity. The regression results showed that, the social class of residents had a significant positive impact on household consumption. One policy suggestion of this paper can be that the relevant departments should fully consider the possibility and complexity of the influence of the social class on the effectiveness of the policy when launching the relevant consumption policy. Specifically, among the various heterogeneous characteristics of residents, the social status of residents greatly affects the actual effectiveness of related consumer policies: For those residents with higher social status, the actual effectiveness of related consumer policies will close to expectations; on the contrary, for those residents with lower social status, the actual effectiveness of the implementation of related consumption policies will undoubtedly deviate from expectations. In this sense, improving the social status of Chinese residents is extremely important, because it directly affects the actual effectiveness of the government's macro-regulation policies such as consumer consumption.

\section{Conflicts of Interest}

The author declares no conflicts of interest regarding the publication of this paper.

\section{References}

[1] Ando, A. and Modigliani, F. (1963) The "Life-Cycle" Hypothesis of Saving: Aggregate Implications and Tests. American Economic Review, 53, 55-84.

[2] Bourdieu, F. (1984) Distinction: A Social Critique of the Judgement of Taste. Harvard University Press, Cambridge, MA.

[3] Zieba, M. (2016) Tourism Flows and the Demand for Regional and City Theatres in Austria. Journal of Cultural Economics, 40, 191-221. https://doi.org/10.1007/s10824-015-9250-9

[4] Cole, H., Mailath, J. and Postlewaite, A. (1998) Class Systems and the Enforcement of Social Norms. Journal of Public Economics, 70, 5-35. https://doi.org/10.1016/s0047-2727(98)00058-9

[5] Corneo, C. and Jeanne, O. (1999) Social Organization in an Endogenous Growth Model. International Economic Review, 40, 711-725. https://doi.org/10.1111/1468-2354.00036

[6] Chan, T. and Goldthorpe, J.H. (2007) Social Stratification and Cultural Consumption: Music in England. European Sociological Review, 23, 1-29.

[7] Rauch, J.E. and Scoppa, V. (2015) Neckties in the Tropics: A Model of International Trade and Cultural Diversity. Canadian Journal of Economics, 42, 809-843.

[8] Treiman, D.J. (2007) Industrialization and Social Stratification. Sociological Inquiry, 40, 207-234.

[9] Hausman, J.A. (1987) Specification Tests in the Econometrics. Journal of the Econometric Society, 46, 1251-1271. 